\title{
O uso do caranguejo maria-farinha Ocypode quadrata (Fabricius) (Crustacea, Ocypodidae) como indicador de impactos antropogênicos em praias arenosas da Ilha de Santa Catarina, Santa Catarina, Brasil
}

\author{
Arno Blankensteyn \\ Departamento de Ecologia e Zoologia, Universidade Federal de Santa Catarina. Campus Trindade, Caixa Postal 476, \\ 88010-970 Florianópolis, Santa Catarina, Brasil.E-mail: arno@ccb.ufsc.br
}

\begin{abstract}
O uso do caranguejo maria-farinha Ocypode quadrata (Fabricius) (Crustacea, Ocypodidae) como indicador de impactos antropogênicos em praias arenosas da Ilha de Santa Catarina, Santa Catarina, Brasil? The most common anthropogenic disturbance on exposed sandy beaches are recreational activities and destruction of sand dunes. To take decisions on manegment of this ecosystems, we must have effective environmental tools, to reduce impacts. The numbers of open burrows of the ghost crab Ocypode quadrata (Fabricius, 1787) should indicate the presence of animals, and in recent years it had been shown that this species is usefull as a tool in rapid assessment of human impacts. To test the hypotesis that anthropogenic impact on sandy beaches reduce the abundance of ghost crabs, the relative abundance (number of burrows $/ \mathrm{m}^{2 i} \mathrm{~N}=60$ ) of the ghost crab 0 . quadrata were compared in three beaches of Santa Catarina Is., southern Brazil. In each one of the beaches, low and strong conditions of human impact were selected. Two levels in the intertidal were analysed, lower and upper midlittoral. The samples were taken in winter/2002 and summer/2003. In winter and summer there were significantly fewer burrows on that beaches with the higher levels of impact. Ingleses beach showed the higher abundances of the ghost crab in both winter and summer. In winter and summer there were significantly fewer burrows at Barra da Lagoa beach. In the summer the lower intertidal showed significantly higher abundances of the ghost crab. The results evidenced that Ingleses beach with high recreational impact had more ghost crabs, probably due to the nocturnal behavior and the fortuitous use of the food detritus left in the beach. In the beach with strong impact of cars and fisheries activities there were no ghost crabs. This study discuss the utility of the world-wide genus Ocypode for a rapid assessment tool of human impacts on exposed sandy beaches.
\end{abstract}

KEY WORDS. Anthropogenic impacts; burrows; density; ghost crab; management.

RESUMO. Os principais impactos antropogênicos em praias arenosas são atividades recreacionais e ocupação desordenada da zona litoral. É necessário um manejo destes ecossistemas, pois representam importantes áreas para a ecologia e economia litorânea, que necessitará de estratégias eficientes para reduzir os impactos. $\mathrm{O}$ número de tocas do caranguejo maria-farinha $O$. quadrata (Fabricius, 1787) indica a presença destes animais na praia. Recentemente foi demonstrado que esta espécie é útil como bioindicadora, podendo representar uma ferramenta para a análise de impactos ambientais. Para testar a hipótese de que os impactos antropogênicos sobre praias arenosas provocam reduções populacionais do caranguejo maria-farinha, a abundância relativa (no.de tocas $/ \mathrm{m}^{2 i} \mathrm{~N}=60$ ) foi comparada em três praias da Ilha de Santa Catarina, sul do Brasil. Em cada praia foram selecionadas duas condições de impactos antropogênicos: reduzido e forte.Para o levantamento foram escolhidos dois níveis mareais, médio litoral inferior e superior e as amostragens foram feitas no inverno/ 2002 e verão/2003. Como resultado, em ambas estações do ano, as abundâncias relativas do 0 . quadrata foram significativamente menores nas praias submetidas a fortes impactos. Considerando as praias, Ingleses apresentou abundâncias relativas do O. quadrata significativamente mais altas, e Barra da Lagoa apresentou as abundâncias relativas menores, tanto no inverno como no verão. Apenas no verão foi registrada a maior abundância relativa do 0 . quadrata no médio litoral inferior. $O$ estudo mostrou que a Praia de Ingleses no local submetido a forte impacto antropogênico continha a maior abundância relativa, provavelmente devido a atividade noturna da espécie e eventual uso dos restos alimentares deixados na praia. Na praia de Pântano do Sul submetida a fortes impactos do trânsito de veículos foi registrada a ausência da espécie. $O$ presente estudo discute a utilidade do gênero cosmopolita Ocypode como ferramenta para a rápida análise de impactos antropogênicos em praias arenosas expostas.

PALAVRAS-CHAVE. Abundância; caranguejo maria-farinha; manejo; impactos antropogênicos. 
Em todo o mundo as praias arenosas vêm sofrendo crescente descaracterização e degradação em razão da ocupação desordenada e crescimento do turismo. No Brasil, particularmente, não há planejamento ambiental adequado e além da intensa especulação imobiliária, os investimentos em infra-estrutura como por exemplo, para o saneamento básico, são escassos. No litoral catarinense a erosão das praias devido aos efeitos naturais como ressacas e também às atividades antropogênicas é mais notável (Gianuca 1997).

Apesar da aparente pobreza das comunidades biológicas, as praias arenosas apresentam uma fauna de invertebrados residentes e que são altamente adaptados às condições adversas predominantes na faixa entre-marés (Veloso et al. 1997) e muitas espécies de vertebrados que usam o ecossistema em alguma fase da sua vida para descanso, reprodução ou alimentação (McLACHLAN 1983). O caranguejo de praias popularmente chamado de mariafarinha ou garuçá, o Ocypode quadrata (Fabricius, 1787) é o organismo mais conspícuo das praias arenosas devido ao seu tamanho relativo e à presença das aberturas de suas tocas. A espécie ocorre tipicamente no médio e supralitoral do ecossistema de praias arenosas em todos os estados morfodinâmicos e sua distribuição geográfica se estende ao longo do Oceano Atlântico ocidental, desde a Flórida (EUA) até o Rio Grande do Sul (MELo 1996).

Devido às dificuldades de amostragens em praias arenosas, considerados ambientes fisicamente controlados por marés, ondas e correntes, poucos estudos foram desenvolvidos para detectar impactos antropogênicos nesses ecossistemas. STEINER \& Leatherman (1981) e Wolcott \& Wolcott (1984) estudaram os impactos do trânsito de carros em praias. Defeo \& de Alava (1995), JaRAmillo et al. (1996) analisaram os efeitos de atividades recreacionais em geral sobre a macrofauna de praias e BRAZEIRO \& Defeo (1999) analisaram os impactos da pesca de bivalves. Steiner \& LeATHERMAn (1981) estudaram o caranguejos maria-farinha em praias do litoral do estado da Virgínia (EUA) e demostraram que locais com muito trânsito de veículos apresentaram as menores densidades populacionais, sendo que em casos extremos os caranguejos não estavam presentes, e locais com muitos pedestres continham maiores densidades devido ao consumo, pelos caranguejos, dos restos de alimentos deixados na praia. BARros (2001) analisou a abundância relativa do Ocypode cordimana (Milne Edwards, 1843) em praias expostas da Austrália tendo concluído que a contagem de tocas é um parâmetro bioindicador útil para análise dos impactos antropogênicos, como ferramenta para a comparação de praias situadas em áreas urbanas e praias distantes de centros urbanos.

As propostas de uso sustentável do litoral brasileiro, através dos documentos de zoneamento, ainda não possuem mecanismos que permitam um rápido acesso para quantificar e qualificar os impactos antropogênicos. Indicadores biológicos poderão ser úteis para a tomada de decisões a respeito da preservação dos ecossistemas. Para conhecer as condições de conservação de um ecossistema, é impossível mensurar todas as variáveis ambientais e integrar apropriadamente uma grande quantidade de informações para colaborar em um processo de tomada de decisões. Por isso, o uso de indicadores biológicos podem se tornar ferramentas importantes.

No litoral catarinense, especialmente na Ilha de Santa Catarina, o turismo é a atividade que mais promove retorno econômico. São mais de 40 praias na ilha que representam o principal foco das atenções para recreação, esportes e lazer. Neste contexto, todas praias apresentam concentrações urbanas onde centralizam-se a infraestrutura de hotelaria, restaurantes, comércio, serviços, pesca e observa-se que os impactos antropogênicos apresentam características similares mas com intensidades variáveis.

O presente trabalho tem como objetivo analisar as abundâncias relativas do O. quadrata em três praias na Ilha de Santa Catarina, sendo que cada uma apresenta condições de fraco e forte impacto antropogênico. A investigação também considera os gradientes da faixa entremarés e da sazonalidade.

\section{MATERIAL E MÉTODOS}

O litoral catarinense, situado na costa sul do Brasil, apresenta $538 \mathrm{~km}$ de extensão e a Ilha de Santa Catarina, localizada no setor central, apresenta $450 \mathrm{~km}^{2}$ de área. A ilha apresenta mais de 40 praias arenosas, com $88 \mathrm{Km}$ de extensão total, e fisiografias extremamente variáveis. As praias oceânicas são separadas por afloramentos rochosos, predominantemente granitos précambrianos sendo as areias tipicamente quartzosas. As marés apresentam padrão de micromarés e regime semidiurno, com amplitude máxima de 1,4 m. (Dhiel \& Horn Filho 1996, Cruz 1998, Horn-FilHo et al. 2002). A classificação climática, segundo Köeppen, é do tipo CFA pela situação em zona intermediária subtropical, pertencente ao grupo mesotérmico úmido, com chuvas distribuídas uniformemente durante o ano. As estações do ano são bem caracterizadas com inverno e verão bem definidos.

As áreas de amostragem foram situadas na Praia de Ingleses, ao norte $\left(27^{\circ} 25^{\prime} \mathrm{S}, 48^{\circ} 23^{\prime} \mathrm{W}\right)$, Praia de Moçambique na porção centro-norte $\left(27^{\circ} 32^{\prime} \mathrm{S}, 48^{\circ} 25^{\prime} \mathrm{W}\right)$ e na Praia do Pântano do Sul, ao sul $\left(27^{\circ} 45^{\prime} \mathrm{S}, 48^{\circ} 30^{\prime} \mathrm{W}\right)$ (Fig. 1). Em cada uma destas praias foi analisado o setor com forte impacto antropogênico por situarem-se junto a um núcleo urbano, caracterizando-se por presença de edificações sobre as dunas acima do supralitoral e atividades turísticas, recreação e comércio ativos na praia. $\mathrm{O}$ setor com fraco impacto, distante dos núcleos urbanos, caracterizando-se pela conservação das dunas e vegetação acima do supralitoral e uso ocasional por turistas. A praia de Moçambique foi usada como setor de pouco impacto e a praia da Barra da Lagoa foi amostrada considerando a situação de muito impacto. A praia do Pântano do Sul foi o setor com forte impacto e a praia de Açores foi amostrada considerando a situação de pouco impacto. A Praia de Ingleses não possui denominações locais, portanto, a porção com forte impacto será chamada de Ingleses Urbano e a porção com pouco impacto será chamada de Ingleses Costão, devido à proximidade, cerca de $500 \mathrm{~m}$, desta formação natural. As praias analisadas no presente estudo 


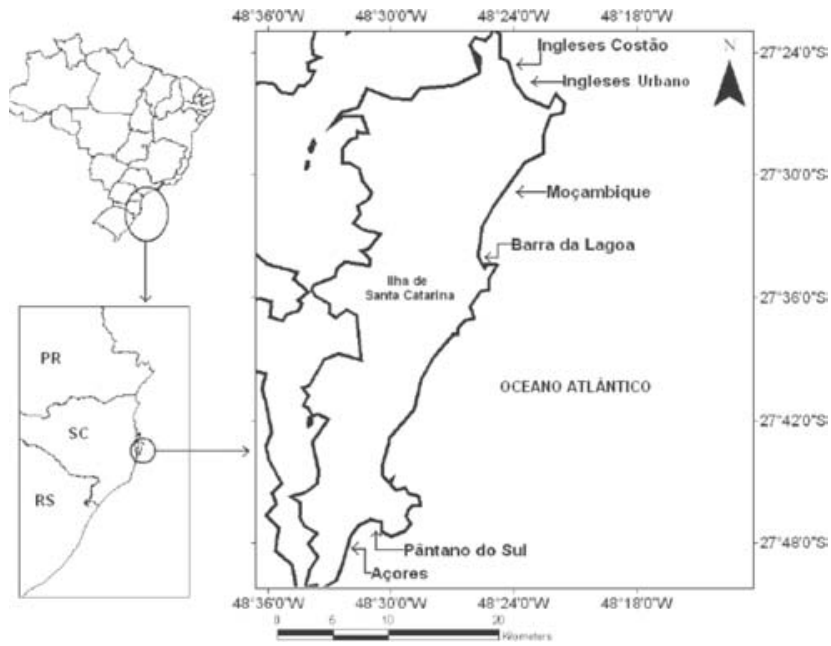

Figura 1. Mapa do Brasil com detalhe do litoral catarinense, indicação da posição geográfica da llha de Santa Catarina e setas indicando as praias estudadas.

apresentam larguras e características granulométricas similares e mais detalhes sobre perfis físicos, sedimentologia e vegetação de dunas das praias da Ilha de Santa Catarina foram fornecidos por Cruz (1998) e Horn Filho et al. (2002).

Os locais de amostragem delimitaram os setores das praias com forte impacto antropogênico (Pântano do Sul, Barra da Lagoa e Ingleses Urbano) e setores com pouco impacto antropogênico (Açores, Moçambique e Ingleses Costão). Nessas duas situações, as tocas ou abertura de galerias de O. quadrata foram contadas em áreas de $1 \mathrm{~m}^{2}$ somando 60 metros quadrados contíguos, em linha paralela com o mar e em dois níveis mareais, o médio litoral superior e inferior. As amostragens foram sempre realizadas nas primeiras horas da manhã com iluminação natural e em duas estações do ano, no inverno (15 a 17/VII/2002) e no verão (20 a 22/III/2003). Foi adotada a análise de variância simétrica (ANOVA) para testar as diferenças das abundâncias relativas de caranguejos em três praias e cada uma apresentando duas intensidades de impacto antropogênico. A ANOVA trifatorial, considerando os fatores intensidade de impacto, praias e níveis mareais foi empregada inicialmente para verificar as variações em cada estação do ano. Posteriormente os dados dos dois níveis praiais foram reunidos para uma nova análise trifatorial, considerando como fatores estação do ano, intensidade de impacto e praias. Todos os dados foram transformados $(\log \mathrm{x}+1) \mathrm{e}$ a homogeneidade das variâncias foi testada com o uso do testeC de Cochran (UNDERWood 1997). Quando a ANOVA acusou significância $(p>0,05)$, foi empregado posteriormente o teste de Tukey de múltiplas comparações entre as médias.

\section{RESULTADOS}

Uma área de $1680 \mathrm{~m}^{2}$ de praia, em dois níveis na região entremarés, foi amostrada totalizando 434 tocas registradas no inverno/2002 e 689 tocas registradas no verão/2003 (Fig. 2). No inverno a maior média de abundância relativa foi registrada na praia de Açores no médio litoral superior com 1,03 tocas $/ \mathrm{m}^{2}$. Ingleses Urbano médio litoral inferior com 0,91 tocas $/ \mathrm{m}^{2}$, Ingleses Costão médio litoral inferior e Açores médio litoral inferior ambas com 0,78 tocas $/ \mathrm{m}^{2}$ foram os demais registros que também apresentaram valores elevados de abundância relativa do O. quadrata. Entretanto, as maiores médias de abundância relativa foram registradas no verão, na praia de Ingleses Urbano médio litoral inferior $\left(2,13\right.$ tocas $\left./ \mathrm{m}^{2}\right)$, Ingleses Costão médio litoral inferior $\left(1,98\right.$ tocas $\left./ \mathrm{m}^{2}\right)$, Moçambique médio litoral inferior e Açores médio litoral superior $\left(1,78\right.$ tocas $\left./ \mathrm{m}^{2}\right)$. Na praia de Pântano do Sul, tanto no inverno como verão, não foram encontrados vestígios da presença de indivíduos adultos de O. quadrata.

Tanto no inverno como no verão (Tab. I) e também na análise estatística que reuniu os dados dos dois níveis mareais estudados para a comparação sazonal (Tab. II), o fator impacto antropogênico isoladamente mostrou que as praias com menor impacto apresentaram abundâncias relativas significativamente maiores. Considerando o fator praia isoladamente, a Praia de Ingleses apresentou as maiores abundâncias do caranguejo (Tab. I). O fator nível na região entremarés, isoladamente, mostrou diferenças significativas com médias maiores no médio litoral inferior (Tab. I). Na interação impacto x praia as maiores abundâncias foram registradas na Praia dos Açores, Ingleses Urbano e Costão (Tab. I ). Na interação impacto x nível no inverno, os setores das praias submetidos a menores impactos antropogênicos no médio litoral superior e inferior apresentaram as maiores abundâncias relativas (Tab. I). Na interação praia x nível no inverno, a Praia de Ingleses Urbano/Costão e no médio litoral inferior e superior e a Praia de Pântano do Sul/Açores, apresentaram as maiores abundâncias relativas (Tab. I). Na interação de praia $\mathrm{x}$ nível no verão, as maiores abundâncias relativas foram registradas no médio litoral inferior de Ingleses, Barra da Lagoa e Moçambique (Tab. I). No inverno a interação dos fatores impacto $\mathrm{x}$ praia $\mathrm{x}$ nível, a Praia de Ingleses Urbano/Costão no médio litoral inferior, o médio litoral superior de Açores e médio litoral inferior de Moçambique apresentaram as maiores abundâncias relativas do caranguejo maria-farinha (Tab. I). Na interação dos fatores estação x praiaa Praia de Ingleses Urbano no verão apresentou as maiores abundâncias do caranguejo maria-farinha (Tab. II). Na interação impacto x praia, as praias de Açores e Ingleses apresentaram abundâncias significativamente maiores do caranguejo O. quadrata (Tab. II).

\section{DISCUSSÃO}

Os principais resultados das ANOVAs trifatoriais mostraram que a hipótese testada foi corroborada para duas praias analisadas, no caso, Praias de Moçambique/Barra da Lagoa e Praias de Açores/Pântano do Sul. Na Praia de Ingleses, as abundâncias médias do caranguejo $O$. quadrata (tocas $/ \mathrm{m}^{2}$ ) não foram significativamente diferentes no setor com impacto antropogênico quando comparadas com aquelas do setor de 

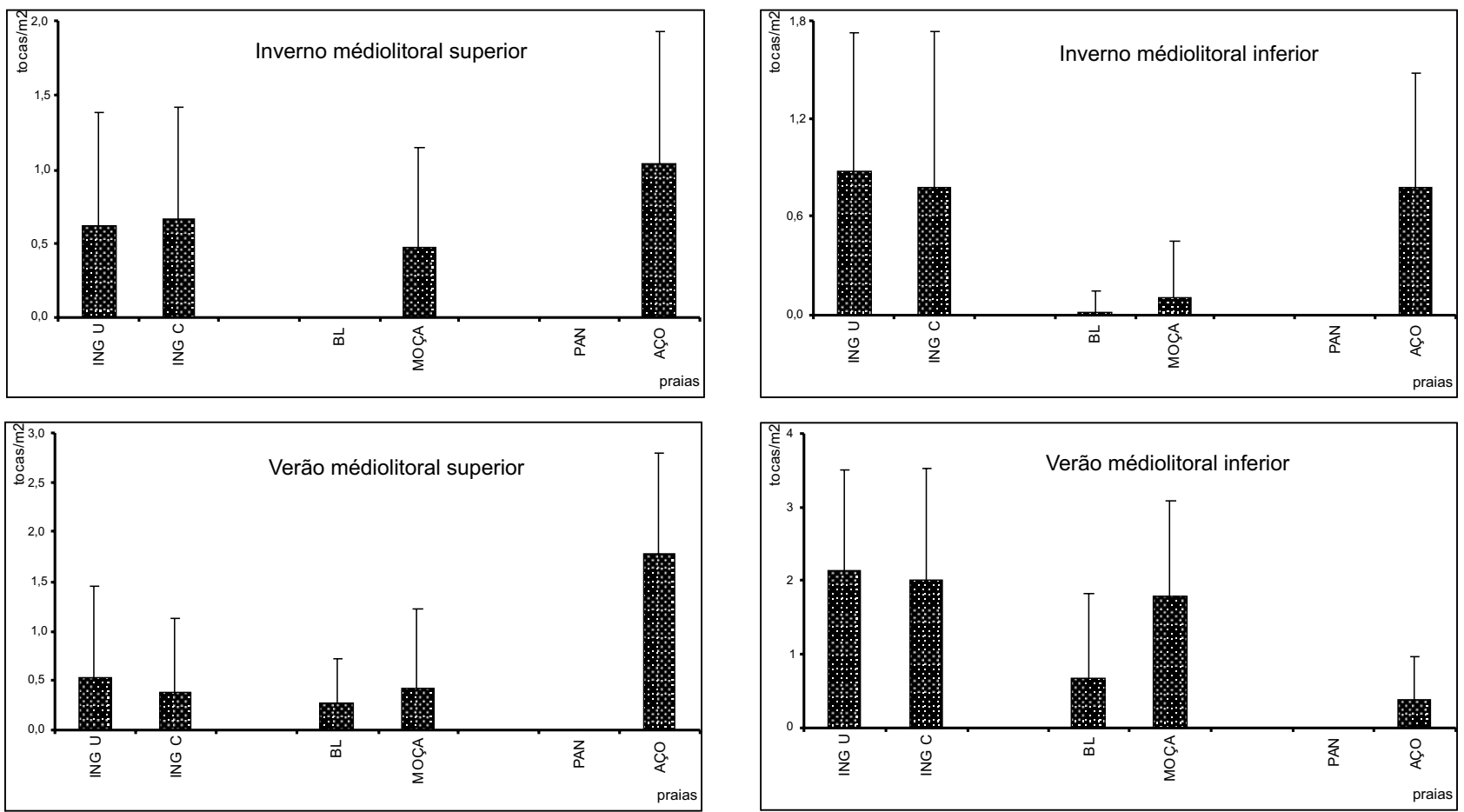

Figura 2. Médias e desvios das abundâncias relativas do O. quadrata em Praias da llha de Santa Catarina. (ING U) Ingleses urbano, (ING C) Ingleses costão, (BL) Barra da Lagoa, (MOÇA) Moçambique, (PAN) Pântano do Sul, (AÇO) Açores.

Tabela I. Resultados da ANOVA trifatorial, considerando os fatores: 1) impacto na praia, 2) praias e 3) níveis mareais para as diferenças nas abundâncias relativas (número de tocas $/ \mathrm{m}^{2}$ ) de O. quadrata em três praias da llha de Santa Catarina no inverno de 2002. Dados transformados segundo Log $(x+1)$. (NS) Não significativo $\left.p>0,05,{ }^{* * *}\right)$ significativo $p<0,001$. Siglas dos nomes das praias: (AÇO) Açores, (BL) Barra da Lagoa, (ING) Ingleses urbano e costão reunidos, (ING C) Ingleses costão, (ING U) Ingleses urbano, (MOÇA) Moçambique, (PAN) Pântano do Sul. Os algarismos 1 e 2 referem-se aos níveis mareais: médio litoral superior (1) e médio litoral inferior (2).

\begin{tabular}{|c|c|c|c|c|}
\hline Fatores e interações & $\mathrm{GL}$ & QM & $\mathrm{F}$ & Tukey \\
\hline \multicolumn{5}{|l|}{ Inverno de 2002} \\
\hline Impacto & 1 & 1,752 & $75,479 * * *$ & Pouco impacto $>$ muito impacto \\
\hline Praia & 2 & 1,314 & $56,615^{* * *}$ & INGU / INGC > PAN / AÇO > MOÇA / BL \\
\hline Níveis & 1 & 0,024 & $1,045 \mathrm{NS}$ & \\
\hline Impacto $\mathrm{x}$ praia & 2 & 0,981 & $42,262 * * *$ & $\mathrm{AÇO}=\mathrm{INGU}=\mathrm{INGC}>\mathrm{MOÇA}>\mathrm{BL}$ \\
\hline Impacto x nível & 1 & 0,183 & 7,889 * & Pouco impacto 1 e $2>$ muito impacto 1 e 2 \\
\hline Praia x nível & 2 & 0,164 & $7,095 *$ & $\begin{array}{l}\text { INGU } / \text { INGC } 2=\mathrm{INGU} / \mathrm{INGC} 1=\mathrm{AÇO} / \mathrm{PAN} 1>\mathrm{AÇO} / \mathrm{PAN} 2=\mathrm{MOÇA} / \\
\mathrm{BL} 1>\mathrm{MOÇA} / \mathrm{BL} 2\end{array}$ \\
\hline Impacto $\times$ praia $\times$ nível & 2 & 0,005 & $0,253 \mathrm{NS}$ & \\
\hline \multicolumn{5}{|l|}{ Verão de 2003} \\
\hline Impacto & 1 & 2,525 & $82,22 * * *$ & Pouco impacto $>$ muito impacto \\
\hline Praia & 2 & 1,252 & $40,77 * \star *$ & INGU / INGC > BL / MOÇA > AÇO / PAN \\
\hline Níveis & 1 & 2,470 & $80,41 * \star *$ & Médio litoral inferior > médio litoral superior \\
\hline Impacto $\mathrm{x}$ praia & 2 & 1,315 & $42,81 * * *$ & $\mathrm{INGU}=\mathrm{AÇO}=\mathrm{INGC}=\mathrm{MOÇA}>\mathrm{BL}$ \\
\hline Impacto x nível & 1 & 0,051 & $1,67 \mathrm{NS}$ & \\
\hline Praia x nível & 2 & 3,541 & $115,28 * * *$ & ING $2>$ BL / MOÇA $2>$ PAN / AÇO $1>\mathrm{ING} 1=\mathrm{BL} / \mathrm{MOÇA} 1>\mathrm{PAN} / \mathrm{AÇO} 2$ \\
\hline Impacto x praia x nível & 2 & 0,994 & $32,36 * * *$ & $\begin{array}{l}\mathrm{INGU2}=\mathrm{INC2}=\mathrm{AÇO} 1=\mathrm{MOÇA} 2>\mathrm{BL} 2=\mathrm{INGU1}=\mathrm{AÇO} 2=\mathrm{MOÇA} 1= \\
\mathrm{INGC1}=\mathrm{BL} 1\end{array}$ \\
\hline
\end{tabular}


Tabela II. Resultados da ANOVA trifatorial, considerando os fatores 1) estação do ano, 2) impacto na praia e 3) praias para as diferenças nas abundâncias relativas (número de tocas $/ \mathrm{m}^{2}$ ) de O. quadrata em três praias da Ilha de Santa Catarina. Dados transformados segundo $\log (x+1)$. (NS) Não significativo $p>0,05,\left({ }^{* *}\right)$ significativo $p<0,001$. Siglas dos nomes das praias: (AÇO) Açores, (BL) Barra da Lagoa, (ING) Ingleses urbano e costão reunidos, (ING C) Ingleses costão, (ING U) Ingleses urbano, (MOÇA) Moçambique, (PAN) Pântano do Sul. Os algarismos 1 e 2 referem-se aos níveis mareais: médio litoral superior (1) e médio litoral inferior (2).

\begin{tabular}{lccrl}
\hline \multicolumn{1}{c}{ Fatores e interações } & GL & QM & F & Tukey \\
\hline Estações & 1 & 2,17 & $61,61 * * *$ & Verão $>$ inverno \\
Impacto & 1 & 4,24 & $120,38 * * *$ & Pouco impacto $>$ muito impacto \\
Praia & 2 & 2,06 & $58,54 * * *$ & INGC / INGU $>$ BL $/$ MOÇA $=$ PAN / AÇO \\
Estação x impacto & 1 & 0,035 & 0,99 NS & \\
Estação x praia & 2 & 0,50 & $14,29 * * *$ & ING U VER $>$ ING U INV $=$ BL VER $>$ AÇO VER = AÇO INV > BL INV \\
Impacto x praia & 2 & 2,24 & $63,61 * * *$ & AÇO = ING U = ING C $>$ MOÇA $>$ BL \\
Estação x impacto x praia & 2 & 0,054 & 1,54 NS & \\
\hline
\end{tabular}

reduzido impacto. A Praia de Ingleses apresentou as maiores abundâncias do caranguejo no verão no médio litoral inferior do local de impacto reduzido e na comparação com as demais praias, as duas condições de impacto analisadas, apresentaram as maiores abundâncias relativas do caranguejo O. quadrata.

Na Praia de Ingleses no setor com forte impacto antropogênico, foram observados os vestígios do uso intenso da faixa entremarés, ou seja, toda a superfície da areia da praia apresentava-se pisoteada, efeito originado devido à prática de esportes e caminhadas. Mesmo nestas condições as aberturas das tocas estavam presentes logo ao amanhecer, e todas com marcas da atividade biogênica recente. Neste caso, durante o dia os caranguejos mantém-se dentro das suas tocas mas as atividades da espécie não são vinculadas aos períodos noturnos ou diurnos e sim às temperaturas, ou seja, entre 14 e $25 \mathrm{C}$ os caranguejos desempenham suas atividades normalmente recolhendo-se nas tocas quando a temperatura vai além desses limites (AlberTo $\&$ Fontoura 1999). Provavelmente, no caso da Praia de Ingleses Urbano, a atividade noturna está ligada ao impacto antropogênico durante o período diurno. Como conseqüência das atividades recreacionais e comercialização de alimentos aos turistas, os caranguejos devem ser beneficiados por restos deixados na praia, e resultado semelhante já havia sido registrado na literatura (Steiner \& Leatherman 1981). Os caranguejos do gênero Ocypode em praias arenosas apresentam dieta alimentar de comedores de detritos sendo que nesses ecossistemas podem ser considerados carniceiros, uma vez que são comuns cadáveres de animais e que são depositados na praia (Jones 1972, Warner 1977, Nybakken 1997). O setor da Praia de Ingleses usada para a verificação da abundância do caranguejo é o de menor largura, comparativamente com as demais praias analisadas (cerca de $20 \mathrm{~m}$ sendo que a Praia de Açores chegava a uma largura de $30 \mathrm{~m}$ ), ou seja, apesar do recurso espaço ser o mais limitante, a espécie tem condições de desenvolver populações relativamente densas. JARAMILLo et al. (1996) também registraram que a macrofauna de praias arenosas expostas do Chile não sofreu impacto antropogênico.
Barros (2001) estudou a abundância relativa de $O$. cordimana em praias na Austrália com objetivo de comparar praias com pouco uso e praias urbanas. Estas últimas apresentavam muros de fixação de dunas sendo que as praias com menos impacto antropogênico apresentaram abundâncias significativamente maiores. $\mathrm{O}$ autor verificou que nos níveis supralitorais das praias investigadas em áreas urbanas, as abundâncias do caranguejo foram menores, e o autor discute que a presença de muros de concreto suprime parte do habitat da espécie. A situação de presença de muros de concreto é semelhante à observada em todas as praias analisadas no presente estudo.

As maiores abundâncias relativas de O. quadrata no médio litoral inferior no verão é um resultado que difere daquele obtido por BARRos (2001) para O. cordimana em praias da Austrália, onde as maiores abundâncias foram registradas no médio litoral superior (com valores de até 4 inds $/ \mathrm{m}^{2} \mathrm{em}$ uma praia - Seven Mile - mas em geral as abundâncias registradas nas praias da Austrália são similares às obtidas nas praias da Ilha de Santa Catarina, ou seja, em torno de 1 ind. $/ \mathrm{m}^{2}$ ). O caranguejo maria-farinha é um cavador de galerias muito hábil de modo que pode rapidamente, em situação de perda da toca, cavar uma nova na areia (WARNER 1977). Esse comportamento também deve estar associado à atividade noturna, que é intensa nesses animais, como predadores de tatuíras e isso pode significar que estes caranguejos constróem tocas em qualquer momento que se faça necessário (BARRASs 1963).

Alberto \& Fontoura (1999) admitiram que condições de ressacas podem provocar migrações de fuga dos caranguejos para faixas do supralitoral. No entanto, as praias estudadas por esses pesquisadores apresentam faixa entremarés larga (mais de $60 \mathrm{~m}$ ) e inclinação suave em direção ao mar, ou seja, as dunas e o supralitoral podem ser utilizados por estes organismos em situações de tempestades costeiras quando as marés podem atingir as dunas. As praias da Ilha de Santa Catarina em geral são estreitas e as faixas do supralitoral são reduzidas e comprimidas contra a vegetação de dunas presente em terreno mais íngreme. Mas é comportamental para o gênero, o uso das 
faixas supralitorais de praias e mesmo no campo de dunas (Veloso et al. 1997). A Praia de Moçambique apresentou maiores abundâncias relativas do O. quadrata do que no setor de forte impacto, a Praia da Barra da Lagoa. Esse resultado foi obtido apesar do fato daquela praia ser a mais exposta à energia oceânica, originada tanto das frentes frias do quadrante sul como grandes ondulações ("swell") originados do quadrante leste. Na Praia de Açores, onde incide a maior energia ambiental devido às frentes frias de sul, em três coletas foram registradas maiores abundâncias do que em Moçambique. Na Praia de Pântano do Sul, a porção submetida ao impacto antropogênico que é similar às demais praias estudadas, observa-se também o trânsito de veículos, principalmente nos meses de verão devido à atividade turística. Nesta porção da praia, não foi registrada a presença de $O$. quadrata e esse resultado de reduzidas abundâncias do O. quadrata em praias com tráfego de veículos já foi obtido em estudos realizados nos EUA (STEINER \& Leatherman 1981, Wolcotт \& Wolcotт 1984).

No presente estudo, foi verificado o predomínio de indivíduos de pequeno tamanho, ou seja, tocas com diâmetro da abertura em torno de $15 \mathrm{~mm}$ no médio litoral inferior, sendo que as populações do caranguejo maria-farinha apresentam uma dinâmica com recrutamento durante todo o ano todo, com mortalidades elevadas ao longo do crescimento e Alberto \& Fontoura (1999) e Françoso et al. (2002) confirmam esse informação para praias de São Paulo e do Rio Grande do Sul, respectivamente. Durante excursões noturnas na Praia de Moçambique, encontramos três fêmeas ovígeras no mês e junho/2003 (estágio final de maturação devido á coloração escura da massa de ovos) o que também foi verificado na Praia do Pinhal, Rio Grande do Sul (Alberto \& Fontoura 1999).

As praias arenosas são o habitat das diversas espécies do gênero Ocypode em torno do mundo nas costas tropicais (WiLLiams 1984, Melo 1986, Brown \& McLaChlan 1990) e as condições oceanográficas em geral não são condicionantes para a abundância desses caranguejos, mesmo em praias abrigadas em setores euhalinos de estuários. A maior oferta do recurso espaço na faixa entremarés das praias permitem que maiores densidades populacionais sejam registradas. As praias analisadas no presente estudo apresentam larguras e características granulométricas similares (Cruz 1998, Horn FiLho 2002). Embora não existam referências sobre o papel de predadores sobre as populações de Ocypode spp. a nível mundial, parte do comportamento noturno observado é devido à necessidade de proteção contra predadores como gaviões e gaivotas (observações pessoais na Praia de Moçambique) e corujas segundo GIANUCA (1997).

A contagem do número de tocas do caranguejo $O$. quadrata para obter estimativas de abundância da espécie, é uma técnica muito rápida e simples (Warren 1990) que pode ser útil em estudos que investigam os impactos antropogênicos em praias arenosas (BARRos 2001). Apesar dos resultados do presente estudo confirmarem a hipótese de trabalho para duas praias analisadas (Ingleses não e Moçambique/Barra da Lagoa e Açores/Pântano do Sul sim) mais estudo devem ser realizados para descrever claramente como as formas de usos das praias afetam as populações do O. quadrata na I. de S. Catarina. Nesse contexto, diferentes pressões podem causar diferentes efeitos em distintos estágios de crescimento, e com conseqüências também diversas sobre as populações dos adultos.

\section{AGRADECIMENTOS}

À Fernanda S. Almeida, Jovelina di Giorgio, Walter Wiedner e a três revisores anônimos.

\section{REFERÊNCIAS BIBLIOGRÁFICAS}

Alberto, R.M.F. \& N.F. Fontoura. 1999. Distribuição e estrutura etária de Ocypode quadrata (Fabricius, 1787) (Crustacea, Decapoda, Ocypodidae) em praia arenosa do litoral sul do Brasil. Revista Brasileira de Biologia, São Carlos, 59 (1): 95-108.

BARRASs, R. 1963. The burrows of Ocypode ceratophalmus (Pallas) (Crustacea, Ocypodidae) on a tidal wave beach at Inhaca Island, Moçambique. Journal of Animal Ecology, Wales, 32 (1): 73-85.

Barros, F. 2001. Ghost crabs as a tool for a rapid assessment of human impacts on exposed sandy beaches. Biological Conservation, Amsterdam, 97 (3): 399-404.

Brazeiro, A. \& O. Defeo. 1999. Effects of harvesting and density dependence on the demography of sandy beach populations: the yellow clam Mesodesma mactroides of Uruguay. Marine Ecology Progress Series, Berlin, 182: 127-135.

Brown, A. \& A. McLachlan. 1990. Ecology of sandy shores. Amsterdam, Elsevier, 290p.

Cruz, O.A. 1998. Ilha de Santa Catarina e o continente próximo. Um estudo de morfologia costeira. Florianópolis, Editora Universidade Federal de Santa Catarina, 280p.

Defeo, O. \& A. Alava. 1995. Effects of human activties on longterm trends in sandy beach populations: the wedge clam Donax hanleyanus in Uruguay. Marine Ecology Progress Series, Berlin, 123: 73-82.

Dhiel, F. \& N.O. Horn FilHo. 1996. Compartimentação geológico-geomorfológica da zona litorânea e planície costeira do Estado de Santa Catarina. Geociências, Notas Técnicas, Florianópolis, 9 (1): 39-50.

Fransozo, M.L.; A. Fransozo \& G. Bertin. 2002. Reproductive cycle and recruitment period of O. quadrata (Decapoda, Ocypodidae) at a sandy beach in southeastern Brazil. Journal of Crustacean Biology, Amsterdam, 22 (1): 157-161.

GianUCA, N.M. 1997. A fauna das dunas costeiras do Rio Grande do Sul. Oecologia Brasiliensis, Rio de Janeiro, 3: 121133.

Horn Filho, N.O.; P.C. Leal \& J.S. de Oliveira. 2002. Atlas das Praias Arenosas da Ilha de Santa Catarina, SC, Brasil. Florianópolis, Editora Universidade Federal de Santa Catarina, 150p.

Revista Brasileira de Zoologia 23 (3): 870-876, setembro 2006 
Jaramillo, E.; H. Contreras \& P. Quijon. 1996. Macroinfauna and human disturbance in Chile. Revista Chilena de Historia Natural, Santiago, 69 (1): 655-663.

Jones, D.A. 1972. Aspects of the ecology and behaviour of Ocypode ceratophtalmus (Pallas) and O. kuhlii de Haan (Crustacea: Ocypodidae). Journal of Experimental Marine Biology and Ecology, Amsterdam, 8 (1): 31-43.

McLachlan, A. 1983. Sandy beach ecology. A review, p. 321380. In: A. McLachlan \& T. Erasmus (Eds). Sandy beaches as ecosystems. The Hague, Junk, 226p.

MeLo, G.A.S. 1986. Manual de identificação dos Brachyura (caranguejos e siris) do litoral brasileiro. São Paulo, FAPESP, Editora Plêiade, 603p.

NyBAKKEn, J.W. 1997. Marine Biology. An ecological approach. Massachussetts, Addison Wesley, XIII+481p.

Steiner, A.J. \& S.P. Leatherman. 1981.Recreational impacts on the distribution of ghost crabs O. quadrata Fab. Biological Conservation, Amsterdam, 20 (2): 111-122.
UnderWOOD, A.J. 1997. Experiments in Ecology. Their logical design and interpretation using analysis of variance. Cambridge, University Press, XX+250p.

Veloso, V.G.; R.S. Cardoso \& D.B. Fonseca. 1997. Adaptações e biologia da macrofauna de praias arenosas expostas com ênfase nas espécies da região entre-marés do litoral fluminense. Oecologia brasiliensis, Rio de Janeiro, 3: 121-133.

Warner, G.F. 1977. The Biology of crabs. New York, van Nostrand Reinhold, 201p.

WARREN, J.H. 1990. The use of open burrows to estimate abundances of intertidal estuarine crabs. Australian Journal of Ecology, Sidney, 15 (3): 277-280.

Williams, A.B. 1984. Shrimps, lobsters and crabs of the Atlantic coast of the eastern United States, Maine to Florida. Washington, Smithsonian Institution Press, 550p.

Wolcotr, T.G. \& D.L. Wolcotr 1984. Impact of off-road vehicles on macroinvertebrates of a mid-Atlantic beach. Biological Conservation, Amsterdam, 29 (3): 217-240.

Recebido em 22.IX.2005; aceito em 29.VIII.2006. 